\title{
FREUD E SEUS LEITORES
}

\section{André Medina Carrone}

André Medina Carrone Universidade Federal de São Paulo (UNIFESP), Professor da Escola de Filosofia, Letras e Ciências

Humanas, Departamento de Filosofia, Guarulhos/SP, Brasil
RESUMO: O presente trabalho procura descrever a relação que Freud estabelece com a figura do leitor em suas Conferências introdutórias à psicanálise e os desafios que esta relação apresenta para a tradução deste texto. As tensões e conflitos presentes neste contato são um prolongamento do conflito psíquico e da dinâmica inconscientes que Freud deseja apresentar a estes leitores. Em seu esforço didático para explicar o núcleo da teoria psicanalítica a partir da investigação de lapsos, sonhos e neuroses, ele elabora sucessivas analogias que também ilustram, por vias indiretas, a natureza do inconsciente psíquico.

Palavras-chave: Psicanálise; tradução; linguagem; interação com o leitor.

ABSTRACT: Freud and his readers. This paper attempts at describing the connection between Freud and the reader in his Introductory Lectures on Psychoanalysis, as well as discussing some of the issues brought by this relation to the work of translating the text into Portuguese. The tensions and conflicts arising from this contact between the author and his audience could be understood as an extension of the psychical conflict and the dynamics of the unconscious Freud is bringing forth to the readers. His attempt to explain the core of psychoanalytical theory from his investigations on lapses, dreams and neurotic symptoms will ultimately create analogies which may also reveal something about the nature of the psychical unconscious.

Keywords: Psychoanalysis; translation; language; awareness of the reader.

DOI - http://dx.doi.org/10.1590/1809-44142017003011 
[Edgar Allan Poe] não era nada difícil na seleção de seu público, e creio que na história o leitor irá encontrar, sem esforço, outras inteligências grandes e originais para quem toda companhia era boa. Certos espíritos, solitários em meio à multidão, e que se alimentam do monólogo, não podem permitir-se a delicadeza em matéria de público. Trata-se, em resumo, de uma espécie de fraternidade fundada no menosprezo. (BAUDELAIRE, 1976, p. 313)

\section{LUGAR INCERTO}

As páginas iniciais das Conferências introdutórias à psicanálise (FREUD, 1917a/1999, p. 12) apresentam oposições que mais nos surpreendem do que esclarecem os objetivos do livro: Freud o descreve como uma introdução despretensiosa e sem maior interesse para quem já conheça as teses principais da psicanálise, e lamenta que temas centrais como o inconsciente tenham sido "recuperados e novamente abandonados em repetidas ocasiões". Em contrapartida a estas limitações, anuncia a presença de um material inédito sobre questões delicadas, como a etiologia da angústia e as fantasias histéricas. Ele recusa igualmente a ideia de que o livro pudesse servir como manual ou substituto para a formação analítica, e, por isso, assinala com nitidez o desacordo entre o ensino e a experiência da psicanálise: quem acompanhar estas conferências não deve imaginar que possa com elas adquirir a técnica para praticá-la, pois "a psicanálise aprende-se na própria pele, pelo estudo da própria personalidade (ibid., p. 12)". Sua advertência ao público que buscava as conferências com este fim não poderia ser mais clara: "Na verdade, eu os desaconselho a virem me ouvir uma segunda vez" (ibid., p. 8).

Mais do que um retrato das opiniões do conferencista sobre a natureza e o alcance de suas comunicações, esta série de contrastes marca o ritmo e o andamento da exposição, renovando-se de forma consistente em todas as suas etapas. O espírito didático de Freud ganha relevo nas conferências sobre os lapsos, onde, após explicar uma simples troca de palavras, nós o vemos anunciar que "esta pequena intervenção e seu resultado, isto já é psicanálise e o modelo de toda investigação (...) que vamos empreender" (ibid., p. 41). No entanto, a ideia de um acesso direto ao método e aos materiais da psicanálise parece caminhar contra a afirmação, feita mais adiante, de que o seu conhecimento exigiria uma longa preparação: “O título 'Introdução à psicanálise' não é mais adequado a esta sessão, que deve tratar das neuroses. A introdução à psicanálise é dada pelo estudo dos lapsos e do sonho; a doutrina das neuroses é a própria psicanálise. Não acredito que pudesse em tão breve tempo lhes fazer tomar conhecimento da doutrina das neuroses de um outro modo que não este, numa forma tão concentrada" (ibid., p. 393). Vemos então que a psicanálise está, por assim dizer, ao alcance de todos e pode ser observada nas ocorrências mais simples, ao mesmo passo que necessita de uma ampla preparação antes que possa realmente ser abordada; e, ainda, que só podemos conhecê-la por um exame da nossa própria personalidade, enquanto o estudo das neuroses, que seria a etapa final de uma longa preparação, é igualmente apresentado como se já fosse a própria psicanálise.

Também é intrigante o desacordo aparente entre o objetivo de instruir um público que nada sabe a respeito da nova disciplina e as queixas recorrentes do autor quanto à forma abreviada e incompleta de suas exposições, mesmo ao tocar em pontos obscuros da teoria. A abrangência e a duração destas conferências pressionam o surgimento de questões nada simples, cuja presença deveria lançar por terra qualquer intenção didática e que demandam sucessivas retificações do autor: "Omiti muitas coisas e precisei ser incompleto em quase todos os pontos" (ibid., p. 245); "estou sensibilizado pelos muitos defeitos das palestras que Ihes dei" (ibid., p. 482). Mas não é a quantidade insuficiente de informações que torna incompleto este trabalho, e, sim, a natureza quase intratável dos temas que uma introdução geral à psicanálise faz despertar. O verdadeiro nó da questão não é a falta de didatismo, mas a presença de um material intangível, que escapa constantemente à explicação por meio de conceitos. São curiosas as semelhanças entre a exigência que Freud faz a esta série de conferências e algumas passagens de trabalhos marcadamente especulativos, nos quais reconhece o alcance limitado dos resultados e a necessidade de aguardar por desenvolvimentos futuros que os confirmem. Em A repressão e Luto e melancolia, dois ensaios que são contemporâneos a estas conferências e estão muito distantes de uma introdução geral à psicanálise, ele admite com tranquilidade que nenhuma elaboração teórica "deixará de ter pontos obscuros" (idem, 1917b/1999, p. 261), e que "a inter-relação dos intrincados problemas psíquicos nos obriga a interromper sem concluir cada investigação” (idem, 2012, p. 87).

E, por fim, quanto mais familiarizado com a psicanálise torna-se o público das Conferências, mais fortemente ele é advertido quanto aos riscos de confundir sua informação teórica com um conhecimento real 
dos fenômenos, ou de sustentar a ilusão de que possa "tornar-se um adepto da psicanálise, com a condição de que no seu caso a análise o poupe" (idem, 1917a/1999, p. 299). Em vez de ser o caminho para a sua formação, seu conhecimento a respeito da psicanálise transforma-se em um obstáculo. Neste sentido, ele também é constantemente informado das fronteiras que o autor fixa para sua própria exposição, como, por exemplo, sua garantia de que "não pretendo despertar conviç̧ões; quero proporcionar estímulos e abalar preconceitos" (ibid., p. 250). Numa palavra, o solo no qual esta introdução faz suas raízes é o conflito.

Se não encontramos conciliação para estes opostos, coisa que Freud não parece inclinado a oferecer, o choque entre estes pares não faz nascer contradições: eles formam a tensão fundamental que sustenta e faz avançar a exposição, formando antes uma ilustração viva da própria psicanálise, para a qual a presença do conflito não significa uma contradição: "a vida psíquica é uma arena e um campo de batalha de tendências opostas... A comprovação de uma determinada tendência não implica na exclusão de outra, oposta a ela; há espaço para ambas. Tudo depende de como os opostos se colocam um em relação ao outro e que efeitos provêm de um e outro" (ibid., p. 72). Este princípio geral certamente se aplica a este texto reto e sinuoso, requintado e simples, despojado e rigoroso, que reúne algumas das páginas mais esclarecedoras de Freud sobre temas espinhosos como simbolismo, hereditariedade e regressão, mas também apresenta o cerne da psicanálise sem abrir mão de referências ao cotidiano de Viena, suas lojas, praças, igrejas e peças de teatro, ou às privações da Grande Guerra e vários ditados populares ("quem dá mais do que tem é um trapaceiro", "tempestade em copo d'água", "pescar em águas turvas", "um bom tempo não dura para sempre") (ibid., p. 258; p. 15; p. 457). A tradução de Marilene Carone deixa transparecer a sutil habilidade de Freud em "usar palavras já conhecidas e de uso corrente para os fenômenos e fatos por ele recém-descobertos" (CARONE, $p$. 188). Sem deixar sinais de separações visíveis ou cortes bruscos, esta versão em português equilibra com habilidade vozes bastante diferentes, que podem aproximar-se do evento mais banal e conhecido por todos ou atirar-se em especulações cujo destino nem o próprio autor pode antecipar. A liberdade de Freud para mesclar estes registros, transitando entre eles sem muita cerimônia, fez destas Conferências a apresentação mais popular de suas ideias, capaz, no entanto, de agradar a um ouvido exigente como o de Adorno, que, em seu curso de sociologia, as descreve como "a melhor introdução existente a todo o plano da psicanálise" (ADORNO, p. 265).

\section{LEITORES EM CENA}

Toda esta diversidade de inscrições está presente porque o trabalho do autor não incide apenas sobre a montagem da teoria. Seu alvo maior, com frequência e regularidade, é o público pelo qual ele espera ser compreendido. Para compreender a arquitetura do livro, é necessário investigar de que maneira Freud fabrica simultaneamente sua teoria e seus leitores, colocando-se na pele de quem o escuta, calculando por antecipação as reações que pode despertar nele. Não estamos diante de uma apresentação doutrinária da psicanálise, realizada a partir de definições gerais, e, sim, de um processo em que a consciência do público registra, avalia e assimila novos conteúdos contra os quais irá resistir, acolhendo de bom grado as opiniões do autor só em ocasiões muito raras. Antes que possa se dar conta, o leitor está enredado pela psicanálise e não tem como se esquivar dela quando, logo na abertura, o conferencista pede aos presentes que não o levem a mal, "se eu os tratar a princípio do mesmo modo como trato estes pacientes neuróticos" (FREUD, 1917a/1999, p. 8). Ao fazer do leitor um dos agentes de seu enredo, o autor o impede de proteger-se por trás da inocência do espectador que observa a uma distância segura o que se passa do outro lado. Freud inicia sua apresentação da psicanálise pela resistência do leitor. Ele antecipa a oposição do público, sabe que não pode contar com sua boa vontade e, por isso, não mede esforços para lhe mostrar que ele é um potencial adversário da psicanálise, e que precisaria se desfazer daquilo que acreditava conhecer, se quisesse compreendê-la. A lenta incorporação das objeções ao processo de construção da teoria desarma o leitor, que cai assim sobre o seu próprio peso, e torna evidente a presença da psicanálise ao dar relevo aos artifícios que ele cria para poder recusá-la. A exemplo do paciente que recusa uma interpretação como absurda, o leitor que rejeita o conteúdo sexual dos sonhos também repete o mecanismo do sonho ao invés de compreendê-lo, sem perceber que comprova esta interpretação precisamente porque não quer aceitá-la; tanto quanto o paciente sob tratamento, o leitor desconhece suas próprias motivações.

Mas esta situação de diálogo que orienta o contato com um público leigo é, na verdade, um desdobramento do antigo diálogo conflituoso consigo mesmo. $O$ antecedente direto para este confronto em voz alta já aparecia em $A$ interpretação dos sonhos, como o confronto solitário de uma pessoa que se desdobra 
em duas, o sonhador e o intérprete do sonho. No quarto capítulo, após o relato do sonho R. é meu tio, ele comenta:

Quando pela manhã o sonho me veio à lembrança, dei risada e disse: "o sonho é uma tolice". Mas ele não cedeu e me acompanhou o dia todo, até que à noite eu enfim me repreendesse: "Se algum paciente seu não dissesse sobre a interpretação de um sonho nada mais do que 'isso é uma tolice', você iria questioná-lo, e suporia que por trás do sonho se esconde uma história desagradável que ele prefere poupar-se de conhecer". Proceda consigo mesmo desse modo; sua opinião de que o sonho seria uma tolice significa apenas uma resistência interna contra a interpretação do sonho. Não se deixe impedir. (FREUD, 1900/1999, p. 143)

Salvo pelo fato de dirigir-se a uma plateia que está objetivamente presente, as Conferências reproduzem esta mesma situação de diálogo. Mas deve-se ter em conta que o papel do interlocutor real foi muitas vezes desempenhado pelo leitor imaginário ou falso, do qual Freud se vale para organizar seus argumentos a partir da fiç̧ão de um diálogo. Os exemplos mais conhecidos desta figura são os "interlocutores apartidários" dos trabalhos tardios A questão da análise leiga (1926) e O futuro de uma ilusão (1927), nos quais ele constrói abertamente o diálogo como uma ficção, e cujos efeitos são bem mais palpáveis do que a invenção daquele interlocutor de Lembranças encobridoras - "um homem de 38 anos com formação acadêmica, que manteve o interesse por questões psicológicas" (FREUD, 1899/1999, p. 538) - por trás do qual está escondido o próprio Freud, que cria, neste caso, a ficção de um diálogo sem pedir a permissão de seus leitores. A apresentação da psicanálise, mesmo quando se ocupa da tarefa mais simples de explicar seus conceitos elementares a um público leigo, se entretece neste outro universo da relação com o leitor, universo no qual ela própria ganha espessura. Sob a discreta aparência do divulgador, Freud desencaminha seus ouvintes ao retirá-los da posição confortável do observador neutro: a psicanálise diz respeito a eles, mesmo que ainda não tenham percebido. Ainda hoje, os leitores destas conferências talvez sejam atingidos pelo mesmo espanto e fascínio do jovem Max Schur, o futuro médico pessoal e biógrafo de Freud que, aos dezoito anos de idade, acompanhou-as na Universidade de Viena:

Ainda posso ver Freud entrar no "Pequeno Auditório" do Instituto de Psiquiatria. Lembrome de escutar pela primeira vez sua voz, que não havia sido ainda desfigurada pelas cirurgias. Eu o vejo à minha frente, de cartola e casaco de pele no inverno. Freud falava sem uma anotação sequer, e mesmo assim tudo o que dizia era publicado quase palavra por palavra. Lembro-me de sua capacidade incomum para antecipar objeções e dúvidas, e do quanto me sentia surpreso quando elas coincidiam com as minhas. Algumas poucas pessoas desapareciam após as primeiras conferências; mas os remanescentes escutavam compenetrados e silenciosos, todos os sábados, das sete às nove da noite. (SCHUR, 1972, p. 306-307)

Ao pressentir no ouvinte a desaprovação de seu próprio pensamento, o conferencista redescobre algo que já conhecia - pois o encontro com a resistência da plateia é, a bem da verdade, um reencontro com as objeções que enfrentou e foi obrigado a superar no trabalho que realizou sobre si mesmo: o leitor de Freud é ele mesmo, antes que descobrisse a psicanálise. $O$ depoimento de Schur nos oferece ainda uma pista para descobrir os efeitos que Freud buscava. Além de elaborar seu argumento na expectativa de vê-lo rejeitado, ele antecipa os termos desta rejeição para que o público não possa mais apoiar-se sobre ela. A exposição adquire assim os contornos de um experimento controlado (sobretudo em sua primeira parte), no qual as teses elementares da psicanálise ganham consistência à medida que entram em choque com as conviç̧ões do leitor. A montagem do texto impõe uma dinâmica que nos lança dentro da psicanálise antes mesmo que se comece a falar sobre ela. Desde o início da primeira conferência, notamos que a trama da exposição é ambivalente, desenvolvendo-se em meio a um jogo constante com a figura do leitor ou ouvinte. $\mathrm{O}$ autor cede à ingenuidade e desinformação do público, mas apenas para iniciar uma exposição negativa da psicanálise, na qual o senso comum funciona como uma espécie de modelo invertido. As certezas deste público leigo, tão afastadas da teoria psicanalítica, são elencadas com paciência e desvelo, e refutadas em seguida a partir de uma nova perspectiva que as desmente por completo. Após recolher a soma das contradições e lacunas da opinião comum (ou da literatura científica), Freud apresenta os termos de um impasse e esboça uma nova 
explicação. Em meio a este processo, a figura do leitor também se transforma e deixa seus rastros no texto: suas opiniões se modificam, as antigas certezas arrefecem e ele acompanha melhor os passos do autor, ora de perto, ora de longe. Não deixa de ser curioso que as diversas vertentes da psicanálise pós-freudiana compreendessem, em uma chave oposta, o papel do "leitor de Freud", ao qual caberia a tarefa de resgatar seu projeto ou intenção fundamental, neutralizando desvios ou equívocos que passaram despercebidos pelo mestre. Mas, o desejo de revelar o destino do texto por uma leitura criativa deixa muitas vezes escapar que este leitor é uma invenção do próprio Freud.

\section{UM LABIRINTO DE INDÍCIOS}

A renovação deste contato com um público relutante é decisiva para a unidade dos materiais que se distribuem nas três partes do livro (Os lapsos, $O$ sonho e Doutrina geral das neuroses). Enquanto as referências a lapsos, sonhos e neuroses são diversas entre si e possuem suas próprias subdivisões, a referência aos caminhos da formação do leitor harmoniza todos estes elementos e facilita a descoberta de equivalências e conexões entre eles. Freud não inicia seu curso por grandes problemas ou teorias nem lança questões fundamentais sem a certeza de que o leitor possa compreender seus termos, preferindo avançar pelas bordas, a passos curtos. O leitor percorre um labirinto de indícios no qual encontra, no princípio, pequenas discrepâncias que tornam insustentável a tese de que "o psíquico é o consciente". À medida que as conexões se multiplicam, "estendendo-se de um ponto para uma parte maior do todo" (FREUD, 1917a/1999, p. 197), começam a se formar estruturas conceituais de maior alcance, nas quais a própria teoria se transforma e cria ramificações que fazem surgir novos conceitos para novos materiais.

As conferências sobre os lapsos revelam o poder da psicanálise para misturar-se às próprias coisas e alcançar tudo o que parece ser mais trivial. Os vestígios de verdade ocultos na fala e nas ações cotidianas são explicados pela interferência entre "tendências perturbadoras" e "tendências perturbadas", e deixam em suspenso oposições simples entre sentido e não-sentido, saber e não-saber: somos obrigados a concluir que o significado destas pequenas expressões nasce sem a nossa permissão, e que só nos damos conta dele quando é tarde demais. O exame do sonho, que, a exemplo do lapso, também pode ocorrer a qualquer pessoa, não nos afasta da psicologia normal. Estamos outra vez diante de um fenômeno comum, cujos mistérios não trazem prejuízo para a vida prática, e que poderia perfeitamente permanecer sem explicação. Mas a interpretação de um sonho exige uma descrição apurada dos processos de transformação da linguagem, das sucessivas inscrições inconscientes e dos mecanismos envolvidos na produção de seu significado. Enquanto o estudo dos lapsos trazia à tona algum propósito, intenção ou lembrança que havia escapado da consciência, a explicação de um sonho nos remete à organização de uma memória inconsciente com dinâmica e regras próprias. Na passagem de um tema a outro, percebemos que a teoria do sonho toma por base aquelas primeiras conclusões sobre os lapsos e acrescenta um conhecimento mais profundo de sua natureza, graças à analogia entre os dois fenômenos e à "íntima conexão existente entre todas as coisas" (FREUD, 1917a/1999, p. 230). O sonho, ao mesmo tempo em que representa um objeto autônomo de investigação, ocupa o lugar de outros objetos. Mais do que preparar o terreno para o estudo das neuroses, ele nos coloca em contato direto com ela, uma vez que "o próprio sonho é também um sintoma neurótico, na verdade um sintoma neurótico que apresenta para nós uma vantagem inestimável: ocorre em todas as pessoas sadias" (ibid., p. 79). A estrutura das conferências é o resultado de uma habilidade diabólica para retratar um objeto distante pela comparação entre outros dois mais próximos. Uma boa parcela do trabalho na "doutrina das neuroses" consiste em uma retomada de resultados anteriores, somada à investigação direta do sintoma - que agora não aparece mais em termos figurados - e de uma questão que não poderia ser apresentada antes: a terapia psicanalítica. Neste longo percurso, a linguagem de Freud também passa por transformações: no estudo dos lapsos predomina a oposição entre dois pólos estáticos, enquanto a ampliação dos materiais que se entrecruzam no sonho exige uma descrição das metamorfoses sofridas por um mesmo conteúdo e das conexões entre suas sucessivas inscrições. Na doutrina das neuroses, a metáfora do combate conquista o primeiro plano. Os movimentos agora se organizam em torno da disputa por um território, dos avanços e recuos durante uma batalha - a libido que "contorna pelo inconsciente" e, ao fim, consegue "abrir caminho para uma satisfação real" (FREUD, 1917a/1999, p. 375) -, das barreiras e fortificações que bloqueiam a ocupação de um espaço disputado por forças opostas, cada uma com seu arsenal e suas estratégias de ataque e defesa. 
Estas conferências contam a história da psicanálise pelo avesso. Iniciam pela expansão do domínio dos fenômenos psíquicos e pela descoberta de suas raízes na vida cotidiana, abordam o sonho e terminam pela clínica das neuroses e da histeria na qual ela teve origem, obedecendo a um plano definido com clareza: "Não vamos (...) seguir este caminho histórico; pelo contrário, vamos tomar o caminho oposto. Queremos demonstrar o sentido dos sonhos como preparação para o estudo das neuroses (...)" (ibid., p. 79). Inversão executada de forma consequente por Freud, como se nota pela transição dos sonhos infantis para os sonhos adultos - nos quais encontrou originalmente o significado geral dos sonhos - e pelo distanciamento que adota ao revisar as contribuições de Bernheim e Charcot ("houve um tempo em que pensávamos que isso era muito simples") (ibid., p. 453). Ao contrário do que se nota em apresentações abreviadas da psicanálise, como as chamadas Cinco Lições ou a Autobiografia intelectual, a sugestão hipnótica, por exemplo, deixa de ser caracterizada como a fonte a partir da qual ganha corpo o conceito de transferência e passa a ser alvo de uma revisão que a descreve como uma variante parcial e incompleta do conceito psicanalítico de transferência.

Freud se apropria, em resumo, das equivalências que estabelece ao descrever um objeto em função de outros, ou ao efetuar uma discreta fusão de vários objetos em um só, o que lhe permite resolver diversos problemas de um só golpe. "Quando a solução de um problema científico é difícil", ele escreve em $A$ interpretação dos sonhos, "muitas vezes pode ser vantajoso acrescentar um segundo problema, mais ou menos como é mais fácil partir duas nozes juntas do que parti-las uma de cada vez" (FREUD, 1900/1999, p. 197). Lembremos que seu desafio não se resumiu à construção de teorias sobre objetos que já existiam: a invenção da psicanálise exigiu também uma nova linguagem que pudesse abordar estes objetos. Nesta série de conferências, os lapsos, sonhos e neuroses ganham existência no texto, sobretudo a partir das relações de semelhança, analogia e parentesco que Freud estabelece entre eles. Assim, a descrição dos eventos a serem investigados se transforma em um primeiro passo rumo à teoria que irá explicá-los, uma vez que o entrelaçamento contínuo de todas as coisas que são tocadas pela psicanálise parece brotar de um solo comum. Para compreender os lapsos, ele afirma: "Será necessário antes explorar a fundo outras áreas obscuras da vida psíquica; só as analogias que lá encontrarmos poderão nos dar a coragem de estabelecer as hipóteses necessárias para um esclarecimento mais profundo" (FREUD, 1917a/1999, p. 61), enquanto a compreensão das neuroses é facilitada pela "impressionante analogia entre a construção do sonho e do sintoma neurótico". O estudo do sonho permanece limitado enquanto não tem início a exposição sobre a neurose, e o leitor deve aguardar por novos elementos se quiser de fato compreendê-lo por completo: "Como ainda não sabemos nada sobre os parentes mais próximos do sonho, os sintomas neuróticos, também aqui precisamos nos contentar com o que já foi conseguido" (ibid., p. 246). A afinidade secreta entre todos estes materiais é o jogo de forças psíquicas que governa o seu funcionamento: "Não queremos apenas descrever e classificar os fenômenos", escreve Freud ao tratar dos lapsos, "mas concebê-los como indícios de um jogo de forças no psiquismo, como manifestação de tendências que visam um objetivo, que trabalham em conjunto ou em oposição umas com as outras. Tentamos portanto chegar a uma concepção dinâmica das manifestações psíquicas" (ibid., p. 62). Na parte final do livro, ele reafirma sua "certeza de que também a neurose se baseia apenas na alteração do jogo de forças entre os poderes da vida psíquica" (ibid., p. 246). Esta busca pela interrelação entre os fenômenos psíquicos, por pontos de contatos ou analogias que comprovem a validade de todo um conjunto de fenômenos, nos devolve à metapsicologia e ao conjunto de ensaios nos quais Freud trabalhava nesta mesma época.

\section{UMA HISTÓRIA DE DOIS LIVROS}

Uma contribuição decisiva do acaso garantiu que este livro viesse a existir. No inverno de 1915, Freud inicia na Universidade de Viena seu curso anual Introdução elementar à psicanálise para uma plateia inusitada de setenta ouvintes, que logo cresce para cem em poucas semanas. Diante do grande interesse, ele passa a redigir suas aulas com antecedência e, segundo o biógrafo Ernest Jones, modifica o plano do curso para transformá-lo no encerramento de sua participação na universidade (JONES, p. 218). O curso coloca um fim à áspera relação de trinta anos de Freud com a Faculdade de Medicina de Viena e começa a ser publicado em 1916 pela Hugo Heller Verlag, em três volumes que correspondiam às três seções que compõem o livro. Mas, para além destas circunstâncias, a mudança repentina atendia a um interesse vital do autor: defender a psicanálise nos anos de guerra. Como se antecipasse o impacto que o livro viria a produzir, ele decide usar a publicação para proteger o movimento psicanalítico. Sob a condição de não suspender o lançamento dos periódicos psicanalíticos que estavam a cargo de sua editora, Hugo Heller receberia dois livros inéditos de 
Freud: as Conferências introdutórias à psicanálise e a Preparação para uma metapsicologia, livro composto por doze ensaios dos quais o autor decidiria publicar apenas cinco. "Descobri o plano que irá deixá-lo em minhas mãos, cedendo a ele a publicação de minhas conferências elementares", ele confidencia a Lou Salomé em novembro de 1915. Pouco antes do Natal, ele anuncia a Ferenczi que "Heller concordou em receber meus dois livros e preservar a Zeitschrift como compensação" (apud SIMITIS, p. 40). A Grande Guerra impõe a Freud um isolamento penoso. São cada vez mais raras as reuniões da Sociedade Psicanalítica de Viena e o trabalho no consultório é escasso; ele atende a três pacientes no início de 1915 e encerra o ano seguinte sem um paciente sequer (JONES, p. 190). A dedicação a um trabalho essencialmente destinado ao público leigo transforma-se em estratégia para a divulgação da psicanálise em tempos adversos, criando um forte contraste com a metapsicologia que o ocupava até pouco antes. Se a grande síntese teórica dos ensaios o pressionava rumo à abstração e ao confronto com ideias ousadas e francamente obscuras, a introdução à psicanálise o deixa em solo bem conhecido. A recapitulação paciente de resultados e argumentos consolidados em trabalhos anteriores, o apego a ilustrações clínicas bem selecionadas, a lenta progressão do particular rumo ao geral, tudo parece contrabalançar a intensa aventura da especulação metapsicológica e confirmar aquela "sucessão de uma imaginação audaciosamente ativa e uma crítica impiedosamente realista" (apud JONES, p. 183) , que definia, segundo ele mesmo, seu processo de criação. Nas Conferências não se respira o ar rarefeito dos ensaios de metapsicologia, mas nem por isso desaparecem ali as ambições teóricas. Tal como o conflito neurótico, o texto de Freud abriga tendências contrárias que não se eliminam. E, se a metapsicologia ficou inacabada, as Conferências permanecem incompletas à sua maneira, encerrando-se fora do texto pelo trabalho de cada leitor que irá descobrir a psicanálise:

Os senhores querem saber apenas de maneira mais geral quais são os caminhos pelos quais atua a terapia psicanalítica e quais são aproximadamente os seus efeitos. E têm o direito indiscutível de fazê-lo. Mas não quero dizer aos senhores: insisto em que o descubram por si mesmos. (FREUD, 1917a/1999, p. 447)

Recebido em: 24 de dezembro de 2015. Aprovado em: 24 de junho de 2016.

\section{REFERÊNCIAS}

ADORNO, T. W. Introdução à Sociologia (Tradução de Wolfgang Leo Maar). São Paulo: EDUNESP, 2007. BAUDELAIRE, C. Edgar Poe, sa vie et ses oeuvres. In: Oeuvres Complètes, vol. 2. Paris: Gallimard, 1976. CARONE, M. Freud em português: Tradução e tradição. In: SOUZA, P. C. (org.) Sigmund Freud e o Gabinete do Dr. Lacan. São Paulo: Brasiliense, 1989, p. 176-188

FREUD, S. Die Traumdeutung (1900). Frankfurt am Main: S. Fischer Verlag, 1999. (Gesammelte Werke, 2/3.)

10.)

Die Verdrängung (1917b). Frankfurt am Main: S. Fischer Verlag, 1999. (Gesammelte Werke, Luto e melancolia. (Tradução de Marilene Carone). São Paulo: Cosacnaify, 2012. Werke, 1.)

Über Deckerinnerungen (1899). Frankfurt am Main: S. Fischer Verlag, 1999. (Gesammelte .Vorlesungen zur Einführung in der Psychanalyse (1917a). Frankfurt am Main: S. Fischer Verlag, 1999. (Gesammelte Werke, 10.)

JONES, E. The life and work of Sigmund Freud, vol. 2 New York: Basic Books, 1953.

SCHUR, M. Freud: Living and Dying, New York: International Universities Press, 1972.

SIMITIS, I. G. Zurück zu Freuds Texten. Frankfurt am Main: S. Fischer Verlag, 1993.

\section{André Medina Carone}

andremedinacarone@gmail.com 